\title{
Epidemiologia e Geografia: O Complexo Patogênico de Max. Sorre
}

\section{Marcelo Urbano Ferreira*}

Apresentam-se alguns traços essenciais do conceito de complexo patogênico, formulado pelo geógrafo francês Max. Sorre, com o objetivo de estimular estudos de integração entre a epidemiologia e a geografia.

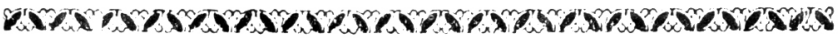

\section{INTRODƯÇÃO}

A crise de um paradigma amplamente aceito em ciências sociais - a teoria dos sistemas, que serve de base à sociologia funcionalista - vem produzindo seus efeitos sobre um conjunto de disciplinas que lidam na interface com a sociologia. Partindo de uma vigorosa crítica à noção de totalidade social da sociologia funcionalista e em conseqüência aos esquemas explicativos (em termos das relações entre as partes e o todo) que dela derivam, a rigorosa análise elaborada por pensadores ligados à Escola de Frankfurt - especialmente Adorno e Habermas - parece ter excedido a capacidade de renovação epistemológica da tradição positivista na sociologia ${ }^{1,4}$. No campo da epidemiologia, cujo poder explicativo reside em grande medida em uma delicada articulação entre dados biológicos e análises sociais, a crise da teoria dos sistemas estimula um duplo esforço teórico. Trata-se, em primeiro lugar, de concluir a ruptura dos estreitos limites a que a epidemiologia foi classicamente restrita ao definir-se (de modo mais ou menos explícito) como descrição quantitativa das doenças em coletividades humanas, demarcando um novo terreno aberto a suas investigações. A seguir, trata-se de elaborar um novo paradigma que venha a substituir a teoria dos sistemas, paradigma que permita enfrentar o problema teórico e prático de interpretar as relações - não compreendidas aqui como mera justaposição - entre fenômenos biológicos e sociais. Deste duplo esforço espera-se a construção de uma noção de causalidade sobre bases mais sólidas e de maior alcance teórico e empírico. As investigações em curso no Brasil e em vários Cadernos de Saúde Pública, RJ, 7(3): 301-309, jul/set, 1991
*Departamento de Parasitologia, Instituto de Ciências Biomédicas, Universidade de São Paulo, Caixa Postal 4365, 01051, São Paulo, SP. 
países da América Latina, bem exemplificadas em uma publicação recente ${ }^{2}$, testemunham a procura de novos paradigmas que sirvam como base a um programa teórico mais abrangente para a epidemiologia.

A geografia vem, de modo análogo, de um contato intenso e prolongado com a teoria dos sistemas e os métodos de análise quantitativa, derivados da sociologia norte-americana ${ }^{3}$. Surge deste contato a corrente autodenominada new geography ou theoretical geography, que, a partir da década de 50, exerceria enorme influência nos meios acadêmicos, especialmente sobre as investigações em geografia física. No Brasil, esta influência pode ser avaliada, por exemplo, pela extensa produção teórica e empírica de A. Christofoletti. Em meio à crise da teoria dos sistemas, a geografia também se viu impelida a uma reconstrução teórica, à procura de paradigmas que fundamentassem uma definição mais precisa de seu objeto de estudo, o espaço humano. Este espaço é, necessariamente, produto de uma série de decisões que orientam sua organização segundo os critérios hegemônicos em uma dada formação econômicosocial. Por isso, este objeto de estudo presta-se a enfoques interdisciplinares - envolvendo a sociologia, a história, a economia, o urbanismo - que exigem da geografia um permanente intercâmbio conceitual. Uma boa apreciação da trajetória recente de geografia encontra-se em uma obra didática, suscinta mas esclarecedora, de Antônio Carlos R. Moraes ${ }^{11}$; cabe aqui somente salientar alguns aspectos do programa teórico da geografia crítica. A geografia nova, ou geografia crítica, não se restringe a elaborar, com maior ou menor grau de sofisticação metodológica, meras descriçōes da paisagem; ocupa-se, prioritariamente, em compreender os processos sociais e econômicos subjacentes às formas de organização espacial que se analisam, empregando associadamente métodos e conceitos de diversas ciencias sociais. Inclui entre seus objetivos, por isso, a organização de campos de investigação interdisciplinar. O papel de pesquisadores brasileiros neste processo de renovação da geografia é extremamente relevante, destacando-se, especialmente, a vasta obra de M. Santos ${ }^{13,8}$.

\section{EPIDEMIOLOGIA E GEOGRAFIA: PRIMEIRAS APROXIMAÇÕES}

O estudo das relações entre o homem e o meio, a que poderíamos chamar de geografia, é empreendido por nume- 
rosos pensadores desde, pelo menos, a Antigüidade Clássica. A descrição de lugares, das paisagens e das sociedades humanas nelas instaladas marca - por exemplo - a História, de Heródoto ${ }^{5}$. Se definirmos estas obras como geográficas, talvez pudéssemos definir Dos ares, dos mares e dos lugares, de Hipócrates, como a primeira obra conhecida a tratar de geografia médica. Porém este rótulo é muito impreciso: não podemos identificar estas obras, de conteúdo muito variado e análise pouco sistemática, à geografia científica tal como a conhecemos hoje. A história da geografia como ciência inicia-se em fins do século XVIII e início do século XIX, quando passa a adquirir certa unidade temática e sistematização; talvez pudéssemos integrar esta produção anterior à "pré-história" da geografia ${ }^{11}$.

Os contatos iniciais entre a geografia científica e a epidemiologia, ambas ainda sob a influência predominante da tradição positivista do século XIX, resultou nos primeiros trabalhos sistemáticos de geografia médica, voltados à descrição minuciosa da distribuição regional das doenças, empregando amplamente recursos cartográficos. Resultaram deste contato os monumentais atlas de geografia médica da segunda metade do século XIX, que orientavam obras de saneamento ambiental e, especialmente, fundamentavam medidas preventivas a serem tomadas pelos exércitos europeus em caso de ocupação militar de territórios insalubres do mundo tropical. Uma revisão interessante (ainda que com espírito crítico pouco aguçado e excessivamente impregnada pela new geography) encontra-se em uma obra coletiva, organizada pelo geógrafo inglês McGlashan ${ }^{9}$, mas talvez nada sintetize melhor seus propósitos que o título atribuído pelo geógrafo francês Yves Lacoste a uma de suas obras mais polêmicas: A geografia serve, antes de mais nada, para fazer a guerra. Também na segunda metade do século XIX surgem os tratados de climatologia médica, elaborados com maior rigor científico que procuram correlacionar a ocorrência das doenças, direta ou indiretamente, com aspectos da geografia física, em especial com as variações climáticas. Estes tratados serão amplamente referidos por Max. Sorre na elaboração de sua geografia médica.

Os primeiros esforços de aproximação entre a geografia e a epidemiologia resultaram, essencialmente, em um intercâmbio de métodos de análise (cartografia, bioestatística), sem haver, no entanto, o desenvolvimento de conceitos que Cadernos de Saude Pública, RJ, 7(3): 301-309, jul/set, 1991 
permitissem uma real articulação interdisciplinar. Desta aproximação inicial surgem trabalhos de caráter descritivo, que se ocupam em estudar padrões de distribuição regional das doenças. A obra coletiva Introdução à geografia médica do Brasil ilustra adequadamente esta tendência ${ }^{6}$. Entre os geógrafos, são bem conhecidas as obras do médico norte-americano J. M. May, que residiu por muitos anos no Vietnã e reuniu grande volume de informações médico-geográficas sobre este pais ${ }^{7}$. A notoriedade de May parece mais relacionada, no entanto, à utilidade imediata que as informações por ele compiladas tiveram durante as operações militares francesas e norte-americanas no Sudoeste Asiático do que a alguma característica essencialmente renovadora de sua obra. Em um célebre artigo publicado em 1950, May sintetiza suas posturas metodológicas: fala em disease-complex, noção claramente tomada de empréstimo a Max. Sorre (que é por ele citado), sem no entanto compreender a novidade deste conceito ${ }^{8}$. Nada em sua obra leva à criação de uma base conceitual própria à geografia médica, capaz de orientar médicos e geógrafos em suas pesquisas práticas $^{20}$. Aqui reside a maior relevância de dois esquemas conceituais, divulgados neste século, que marcam uma nova fase nas relações entre a geografia e a epidemiologia justamente por permitirem uma interação ao mesmo tempo teórica e metodológica. Na União Soviética, o parasitologista Y.N. Pavlovsky apresenta, em 1939, perante a Academia de Ciências da URSS, a primeira formulação de sua teoria dos focos naturais das doenças humanas ${ }^{12}$, que durante três décadas orientaria diretamente as investigações sobre o impacto epidemiológico decorrente da ocupação pelo homem de extensas porções semidesertas do território soviético. Pavlovsky recolhe elementos de abordagens ecológicas da epidemiologia, comuns a vários autores que o precedem; seu mérito não está em um possível caráter inovador de sua obra, mas especialmente na divulgação de um conjunto coerente de idéias aplicáveis a estudos de campo. No Brasil, Pavlovsky seria conhecido especialmente pela enorme influência que seus escritos exerceriam sobre a escola parasitológica de S. B. Pessoa. Na França, Maximillien (Max.) Sorre, geógrafo acadêmico de sólida formação clássica, publica em 1943 o primeiro volume (de uma série de três) de sua obra máxima, Les fondements de la géographie humaine, que trata de seus fundamentos biológicos. Sorre orientava-se, essencialmente, por uma preocupação teórica: fornecer uma base conceitual à geo-

Cadernos de Saúde Pública, RJ, 7(3): 301-309, jul/set, 1991 
grafia médica que permitisse investigações de natureza interdisciplinar. A semelhança entre ambos os esquemas conceituais é evidente, especialmente porque ambos partem de uma interpretação ecológica das relações entre o homem e o meio.

Mas, diferentemente de Sorre, as idéias divulgadas por Pavlovsky são muito debatidas no Brasil. $O$ mérito maior pelo atual revigoramento deste debate cabe, certamente, a L. Jacintho da Silva, que elabora uma análise extremamente fecunda e original sobre a evolução da doença de Chagas no Estado de São Paulo com base em uma reformulação crítica do conceito de foco natural das doenças ${ }^{19}$. Seu trabalho teórico consiste em reelaborar o esquema conceitual de Pavlovsky à luz da geografia crítica (inspirado especialmente por $M$. Santos), radicalizando o sentido original da noção de foco antropúrgico (isto é, criado pela ação humana sobre a natureza) e destacando a utilidade deste conceito para expressar a determinação social das formas de ocupação do espaço e de distribuição das doenças neste espaço transformado pela ação humana. A inspiração ecológica de Pavlovsky é, portanto, reformulada em termos de uma relação homem-meio, cuja análise recai no âmbito das ciências econômicas e sociais.

Por que apresentar hoje as idéias de Sorre, que tão pouco impacto tiveram sobre a epidemiologia no Brasil? O objetivo maior desta comunicação é inspirar investigações ulteriores, que reelaborem o conceito original de complexo patogénico de modo a torná-lo um poderoso instrumento de análise e de integração entre as ciências do espaço (entre as quais a geografia) e a epidemiologia.

\section{O COMPLEXO PATOGENNICO DE MAX. SORRE}

Les fondements de la géographie humaine, em cujo primeiro tomo Sorre lança as bases teóricas de sua geografia médica, é um dos empreendimentos intelectuais mais notáveis da geografia neste século, que estabelece inúmeros pontos de contato entre a geografia e as ciências sociais e biológicas, contato que marcaria a obra geográfica de Sorre ${ }^{10}$. Nos limites teóricos impostos pela abordagem ecológica das relações entre o homem e o meio, que marca a obra de Sorre, o conceito de complexo patogênico amplia o poder analítico e explicativo de uma geografia antes restrita quase exclusivamente à descrição do meio físico. 
Sua formulação parte do estudo das doenças infecciosas e parasitárias, que alcançara enorme desenvolvimento nos primeiros anos deste século:

$\mathrm{Na}$ complexidade das relações que interessam a uma só vez ao biólogo e ao médico, procura-se uma noção sintética capaz de orientar as pesquisas do geógrafo. A interdependência dos organismos postos em jogo na produção de uma mesma doença infecciosa permite inferir uma unidade biológica de ordem superior: o complexo patogênico. Compreende, além do homem e do agente causal da doença, seus vetores e todos os seres que condicionam ou comprometem sua existência. (...) Tendo por base esta noção é que nos propomos a fundar o capitulo mais vasto da geografia médica, o das doenças infecciosas; sem ela, este nada seria senão uma coleção de fatos desprovidos de ligação e de alcance cientifico. $^{22}$

Os complexos patogênicos recebem o nome da doença a que se referem: fala-se, portanto, em complexo malárico, da peste, da doença do sono. Salienta-se não se tratar de "séries lineares reduzidas a um número limitado de termos", mas sim de "grupos que se enredam de maneira muitas vezes inextricável". Na abordagem ecológica de Sorre, os complexos têm sua vida própria, sua origem, seu desenvolvimento e sua desintegração - sugerindo uma análise epidemiológica evolutiva, de cunho histórico. O papel do homem na gênese e desintegração dos complexos não se restringe à sua atuação como hospedeiro ou vetor das doenças (ou seja, ao plano biológico); Sorre ocupa-se com a ação humana de transformação do ambiente e com seu possivel impacto epidemiológico, mas subordina a análise da atividade humana de transformação do espaço à sua noção ecológica de gênero de vida ${ }^{21}$. Sua análise sobre a gênese do complexo da febre amarela no Brasil é exemplo deste procedimento:

Nas primeiras décadas deste século, quando a febre amarela em sua forma urbana estava em vias de extinção no litoral brasileiro, chamava atençāo a febre florestal nos estados do Sul, Rio, Minas, São Paulo. Assinalava-se alguma epizootia em macacos Allouata em uma época em que os desmatamentos estavam em plena atividade es homens não apresentavam imunidade alguma aos casos 
de febre amarela que sobrevinham nas cidades. Ora, com as crises econômicas, havia menos homens; menos macacos e menos mosquitos também, em conseqüência do desmatamento. E a doença propagou-se rapidamente, acompanhando o progresso dos transportes. A epizootia precede a epidemia. Os macacos Allouata calaram-se como que estupefatos por uma mortalidade incomum $e$ seu silêncio impressionou as populą̧ōes vizinhas. Eis portanto uma doença que apareceu depois de pouco tempo; hoje ela ameaça os paises quentes do velho mundo. ${ }^{22}$

Nos Fondements Sorre exemplifica seu método, descrevendo os complexos patogênicos da malária, da doença do sono e da peste. No capítulo Geografia médica $e$ ecúmeno, apresenta um amplo quadro da geografia médica do Mediterrâneo reunindo um volume impressionante de informações biológicas e geográficas, incluindo dados detalhados sobre o clima e empregando largamente recursos cartográficos. Seu conceito de complexo patogênico permite-lhe abordar grande variedade de doenças infecciosas e parasitárias, ao passo que a teoria de Pavlovsky se limita ao estudo das doenças de animais transmissiveis ao homem, que teriam seu foco natural (em geral um reservatório silvestre). A malária humana, por exemplo, que Sorre estuda com certo pormenor, é uma doença sem foco natural não-humano (à exceção, talvez, das infecções por Plasmoclium malariae, cuja transmissão do macaco ao homem está sob intensa investigação atualmente), à qual não se poderia aplicar a teoria de Pavlovsky.

$\mathrm{Na}$ perspectiva ecológica de Sorre, as relações entre o homem e o meio compreendem a ação da natureza (meio físico e biológico) sobre o homem e a ação humana, modelando a natureza. Esta abordagem está bem desenvolvida, também, no livro em que Sorre analisa as migrações humanas de uma perspectiva geográfica e sociológica ${ }^{23}$. Sua diferença em relação à geografia crítica - particularmente pelo fato desta abandonar o paradigma sistêmico - reside na definição de seu objeto de estudo. A geografia crítica estuda o espaço humano, o espaço construído pelo homem. E não há espaço físico isento de ação do homem organizado em sociedade, indiferente às decisões espaciais humanas. A base explicativa da geografia crítica não está na elucidação de uma teia infindável de influências recíprocas entre o homem e o meio, mas especialmente nas necessidades 
históricas, sociais e econômicas que produzem um determinado modo de organizar o espaço.

A idéia de ação humana organizando o espaço não é estranha à noção de complexo patogênico: trata-se somente de aprofundá-la, de recolocá-la a serviço de uma epidemiologia que procura compreender os processos subjacentes aos fenômenos que analisa. Tomá-la, em suma, como aquilo a que se destinava originalmente: o complexo patogênico como um conceito sintético, de interação, sujeito às reformulações críticas que se tornarem necessárias à medida que se aprimoram as técnicas e os conceitos empregados pela geografia.

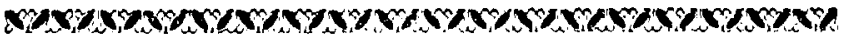

Some essential features of the pathogenic complex concept formulated by the French geographer Max. Sorre are presented, aiming at integrating epidemiological and geografic studies.

\section{REFERÊNCIAS BIBLIOGRÁFICAS}

1 - ADORNO, T.W. Introdução à controvérsia sobre o positivismo na sociologia alemã. Em: Textos escolhidos/Walter Benjamim, Max Horkheimer, Theodor W. Adorno, Jurgen Habermas. (Col. Os pensadores). 2! ed. São Paulo, Abril cultural, 1983, p. 209-268.

2 - ALMEIDA FILHO, N. Epidemiologia sem números. Rio de Janeiro, Campus, 1989.

3 - CHISTOFOLETTI, A. Análise de sistemas em geografia. São Paulo, Hucitec/Edusp, 1979.

4 - HABERMAS, J. Teoria analítica da ciência e dialética. Em: Textos escolhidos/Walter Benjamin, Max Horkheimer, Theodor W. Adorno, Jurgen Habermas. (Col. Os pensadores). 24. ed. São Paulo, Abril Cultural, 1983, p. 271-299.

5 - HERÓDOTOS. História. Trad. de Mário da Gama Kury. Brasilia, Editora Universidade de Brasilia, 1985.

6 - LACAZ, C. S.; BASRUZZI, R. G. \& SIQUEIRA, w.(org.) Introdução à geografia médica do Brasil. São Paulo, Edgard Blücher/Edusp, 1972.

7 - LEARMONTH, A.T.A. Medicine and medical geography. Em MCGLASHAN, N. D. (org.) Medical geography. Londres, Methuen, 1972, p. 17-42. 
8 - MAY, J.M. Medical geography: its methods and objectives. Georgr. Rev. 40: 9-41, 1950.

9 - McGLASHAN, N. D. Medical geography: an introduction. Em: McGLASHAN, N. D. (org.), op. cit., p. 3-15.

10 - MEGALE, J.F. A geografia torna-se uma ciência social. Em: MEGALE, J.F. (org.) Max. Sorre: geografia. (Col. Grandes cientistas sociais) São Paulo, Ática, 1984, p. 729.

11 - MORAES, A.C.R. Geografia: uma pequena história crítica. 3! ed. São Paulo, Hucitec, 1984.

12 - PAVLOVSKY, Y. N. (org.) Human diseases with natural foci. Moscou, Foreign Languages Publishing House, s.d.

13 - SANTOS, M. Pobreza urbana. São Paulo, Hucitec, 1979.

14 - SANTOS, M. Ensaios sobre a urbanizą̧ão latino-americana. São Paulo, Hucitec, 1982.

15 - SANTOS, M. Espaço e método. São Paulo, Nobel, 1985.

16 - SANTOS, M. Por uma geografia nova. 3! ed. São Paulo, Hucitec, 1986.

17 - SANTOS, M. \& SOUZA, M. A. A. (org.) O espaço interdisciplinar. São Paulo, Nobel, 1986.

18 - SANTOS, M. \& SOUZA, M. A.A. (org.) A construção do espaço. São Paulo, Nobel, 1986.

19 - SILVA, L. J. Evolução da doença de Chagas no Estado de São Paulo. Ribeirão Preto, 1981.(Tese de Doutoramento, Faculdade de Medicina de Ribeirão Preto, USP).

20 - SOBRAL, H. R. W. Poluição do ar e doenças respiratórias em crianças da Grande São Paulo: um estudo de geografia médica. São Paulo, 1988. Tese de Doutoramento, Faculdade de Filosofia, Letras e Ciências Humanas, USP.

21 - SORRE, M. A noção de gênero de vida e sua evolução. Em: MEGALE, J. F. (org.), op. cit., p. 99-123.

22 - SORRE, M. Les fondements de la géographie humaine. Primeiro tomo: Les fondements biologiques (Essai d'une écologie de l'homme). 3! ed., revista e ampliada. Paris, Armand Colin, 1951.

23 - SORRE, M. Les migrations des peuples. Paris, Flammarion, 1955. 